\title{
Predicting project duration and cost, and selecting the best action plan using statistical methods for earned value management
}

\author{
Sajad Soltan $^{\mathrm{a}^{*}}$ and Maryam Ashrafi ${ }^{\mathrm{a}}$
}

${ }^{a}$ Department of Industrial Engineering \& Management Systems, Amirkabir University of Technology, Tehran, Iran

\begin{tabular}{l}
\hline C H R O N I C L E \\
\hline Article history: \\
Received: March 12020 \\
Received in revised format: \\
March 72020 \\
Accepted: March 192020 \\
Available online: \\
March 19 2020 \\
\hline Keywords: \\
Project management \\
Earned value management \\
Control charts \\
Action plan selection \\
Duration forecasting \\
Cost forecasting \\
Empirical database
\end{tabular}

\section{Introduction}

In today's world, planning and controlling are essential issues in project management that have numerous effects on the different fields of the projects, such as lowering the project duration and cost (Ghorbani et al., 2019). Measuring project performance and determining project progress comparing to its baseline has always been a concern of project managers. They are enthusiastic about finding simple ways to denoting project performance. One of the most effective project management methods is the earned value management method. This method was first used in 1960 as a method of financial analysis in the defense industry of the USA. In 1967, this method was used for financial control and analysis. Then, with the expansion of this method, a standard named ANSI EIA 748-A, was published in the United States (Valle, 2006). Finally, this method was used as the most crucial method of project performance control in the project management standard in 2000 . After that, the first and second standardized versions of the practice standard for earned value management acquired by the American Project Management Institute in 2005 and 2011, respectively * Corresponding author.

E-mail address: $\underline{\text { Sajadsoltan@aut.ac.ir }}$ (S. Soltan) 
(Fleming \& Koppelman, 2016). This method and its indicators, provide the possibility of checking the current status of the project and its performance. Indicators of this method also facilitate the prediction of the future status of projects. Since earned value management is one of the crucial components of project management and control, a significant stream of research has been conducted to earned value management from various perspectives in recent years. Furthermore, multiple extensions of traditional EVM forecasting approaches have been proposed (Batselier \& Vanhoucke, 2017). These researches are about the application of statistical methods in predicting project duration and cost using earned value management indices. Among these researches, we can refer to Liu and Lin (2008), who set up individual control charts for CPI and CPI-1 to evaluate project performance. In another study, Hunter et al. (2014) focus on the implementation of earned value management method on the RBSP projects and analyze the benefits of this method to provide insight into cost/benefits considerations considering implementation of this method. Mortaji et al. (2015) use change point analysis to extend a relatively reliable cost and performance indicators. They show how that model can be used to obtain more accurate estimates for the final cost and duration of the projects. Moreover, Chen et al. (2016) proposed a method for improving the predictive power of planned value, and also developed the model for four case projects. Baqerin et al. (2016) presented a model to conduct an estimation of schedule performance. Their model concentrated on the recurring nature of the main activities to forecast schedule performance. Also, Khamooshi and Golafshani (2014) developed a method that decupled schedule and cost performance measures. They also introduced new indicators that have broader applications to measure schedule performance.

In all of the aforementioned researches in the literature, the earned value management approach has been used as a way to control and predict the status of projects on a deterministic basis, which can be incorrect considering project risks. Besides, the project phases are not considered in calculating the earned value management indicators, whereas project phases are different from each other. Moreover, these researches focused on the estimation, and action plan selection is not be considered. Thus, the purpose of this paper is to present a method to project duration and cost estimation and best action plan selection using statistical methods. This method will provide a confidence interval to predict project duration and cost in each phase. This method also suggests the best action plan using expert judgment. Since the proposed method is used in each phase separately, the accuracy of this method will be increased.

This paper is structured as follows. In the second section, the concept of earned value management is described. The proposed method is presented in section 3 . The validity of the presented method is examined in the fourth section. Finally, conclusions of this research and suggestions for future research are delineated in section 5 .

\section{Concepts and definitions}

This section explains the concepts related to research, such as the method of earned value management and earned schedule.

\subsection{Earned Value Management}

Earned value management is a systematic way of integrating, measuring, and comparing trends of cost, time, and scope in a project (PMBOK, 2017). This method is one of the most common tools for evaluating project performance. This method has three main parameters that are discussed below (Valle, 2006):

Planned Value (PV): It means the budget of planned works. The budget of all activities that should have been spent according to the plan. Planned value is obtained by multiplying the percentage of project progress by the project budget.

Earned Value (EV): It is the value of work done. The earned value for each activity is obtained by multiplying the percentage of actual activity progress in the project budget. 
Actual Cost (AC): It is the actual cost spent on the performed activities, including all fixed and variable costs.

Budget at Completion (BAC): It is the planned cost of the entire project. Budget at Completion is equal to the planned value at the final stage of the project.

Based on the above indices, other indices can be calculated, which provide more accurate information about the current status of the project. Some essential indicators in the earned value management method are presented below:

Cost Variance (CV): This indicator shows the difference between the earned value and the actual cost that is calculated in Eq. (1):

$$
C V=E V-A C \text {. }
$$

Schedule Variance (SV): This indicator shows the difference between the earned value and planned value, which is shown in Eq. (2):

$$
S V=E V-P V .
$$

Cost Performance Index (CPI): This indicator is recognized as a measure of the cost-effectiveness achieved through Eq. (3):

$$
C P I=\frac{E V}{A C} \text {. }
$$

Schedule Performance Index (SPI): This indicator is used to measure the scheduling performance of projects, as shown in Eq. (4):

$$
S P I=\frac{E V}{P V} \text {. }
$$

In addition to these indicators, the earned value management method has some indicators to predict the future status of projects. This forecast has a relation with the schedule or cost performance of projects. One of the most important predictors in the earned value method is estimated cost at completion $(E A C(c))$. This index is calculated as shown in Eq. (5):

$$
E A C(c)=A C+\frac{B A C-E V}{C P I}
$$

\subsection{Earned Schedule}

The earned schedule method is a part of the earned value method that has a different approach toward measuring schedule indices. This method was first introduced by Walter Lipke (2003). In this method, it was shown that the values of schedule variance and schedule performance index by the earned value method would be zero and one respectively, when projects are completed with delay. It means that although projects are not completed on planned duration, the schedule indices show that the project has been finished on time. In other words, those two mentioned indices undergo sudden changes in their trends (Colin and Vanhoucke, 2016). It also happens after the end of projects. Moreover, since the schedule performance index is expressed in monetary terms, a method is needed to calculate project schedule indices. Therefore, the earned schedule method is used to calculate the schedule variance and schedule performance index. This method helps us calculate project schedule performance based on a time unit. The earned schedule can be calculated as depicted in Eq. (6) (Lipke, 2003):

$$
E S=C+I,
$$


where $C$ is obtained by comparing the earned value based on planned values in each period. The method of calculating the value of $I$ is also shown in Eq. (7):

$$
I=\frac{E V-P V_{C}}{P V_{C+1}-P V_{C}}
$$

Using the earned schedule method, the time-related indices can be obtained in a new way. Schedule Variance (SV) and Schedule Performance Index (SPI (t)) are obtained using Eqs. (8) and (9), respectively:

$$
\begin{aligned}
& S V(t)=E S-A T, \\
& S P I(t)=\frac{E S}{A T},
\end{aligned}
$$

where $A T$ is the time of measurement of the earned value index. The calculation of the schedule variance and the schedule performance index are instead based on the horizontal axis (time) than the vertical axis (cost).

Similar to the estimated cost at completion, there is also an indicator named estimated duration at completion $(E A C(t))$, as shown in Eq. (10) (Martens and Vanhoucke, 2018):

$$
E A C(t)=A T+\frac{P D-E S}{S P I(t)} .
$$

\section{The proposed method}

In this section, the prediction method is presented. First, the relevant indicators are introduced, then the prediction of these indices is made by a control chart. Finally, the best action plan is selected.

\subsection{Indicators selection}

The control chart is one of the methods of quality control. Thus, by determining the mean and standard deviation of a variable, the control chart can be applied for any variable. The limit bars of the control chart vary depending on the rate of first-type error $(\alpha)$. Also, the probability distribution function of the variables must be determined. Since the variables follow Normal distribution, the accuracy of control charts and its limit increases. This study aims to use indices to plot control charts in which indicate the status of the project and follow Normal distribution. Since time and cost are identified as two measurable factors in project management, indicators that represent these two factors are used. According to Lipke (2002), the probability distribution function of the earned value indices, as well as the earned schedule, was examined. Various tests were employed to investigate the normality of the indices, including the Kolmogorov-Smirnov test, Chi-Square test and Anderson-Darling test. The indices examined in that study are, $C P I^{-1}, L n C P I^{-1}, S P I^{-1}, C V$, $\operatorname{LnSPI}^{-1}$, and $\operatorname{Ln} S P I(t)^{-1}$. Finally, the result showed that the indices follow the Normal distribution. As these two indices represent the project performance in terms of time and cost, respectively, they are selected for drawing the control chart.

\subsection{Drawing a control chart for indicators}

In this step, the control charts are drawn for the selected indices. It is to be mentioned that control limits are used for a process. An important feature of the process is that it performs a repetitive activity over a long time. So, there is no need to change the initial process control limit for next times, because the process does what it is supposed to do in the long run when it starts. However, the nature of the project is somewhat different from the process. Due to the uncertain nature of 
projects, a fixed control limit cannot be used to evaluate the performance of a project during its lifecycle, and different control limits should be used depending on the project phase as well as the activities carried out there. Besides, projects have a definite start date and finish date and are not similar in the long run. So, there is a need for a factor to adjust the control limits. In another study, Lipke et al. (2009) explored the use of statistical methods in the earned value management indicators as well as the earned schedule indicators to predict project output. This study introduces factors called adjustment factors for schedule and cost performance indices. The method of calculation of these factors is shown, respectively, for the adjustment factor for schedule and cost in Eq. (11) and Eq. (12) (Lipke et al., 2009):

$$
\begin{aligned}
& A F_{s}=\sqrt{\frac{P D-E S}{P D-\frac{E S}{n}}} \\
& A F_{c}=\sqrt{\frac{B A C-E V}{B A C-\frac{E V}{n}}}
\end{aligned}
$$

where $n$ is the time of index calculation, and $P D$ is the planned duration for the project. Concerning the mentioned control chart material and the considerations that should be considered for using these charts for the project, the limits for controlling the schedule performance index and the cost performance index can be obtained using Eqs. (13) and (14), respectively:

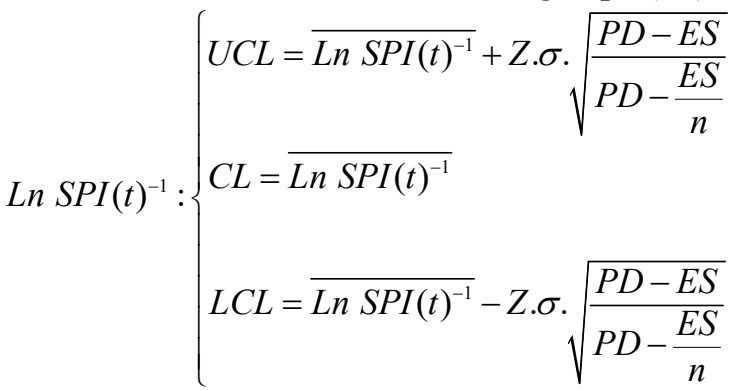

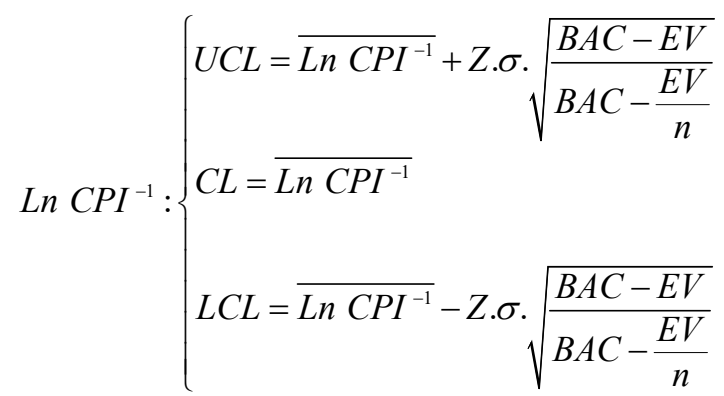

\subsection{Predicting the duration and cost of projects}

Using the upper and lower control limit for each indicator, one can make the most optimistic and pessimistic forecasts for project duration and cost, and provide predicting intervals. Since the natural inverse logarithm of the indices is used to plot the control chart, the highest index value that corresponds to the best project performance according to the indices is the lower control limit of each index. Similarly, the lowest index value is equal to the upper control limit of the index.

\subsubsection{Predicting the duration and cost at completion}

Using the upper and lower control limit calculated for the $\operatorname{Ln} S P I(t)^{-1}$, an optimistic and a pessimistic prediction for completion duration of the project are calculated using (15) and (16), respectively:

$$
\begin{aligned}
& E A C(t)_{O}=A T+\frac{P D-E S}{e^{U C L\left(L n S P I(t)^{-1}\right)}} \\
& E A C(t)_{P}=A T+\frac{P D-E S}{e^{L C L\left(\operatorname{LnSPI}(t)^{-1}\right)}}
\end{aligned}
$$


where, $E A C(t)_{O}$ and $E A C(t)_{P}$ represent the optimistic and pessimistic prediction for the completion duration of the project respectively.

Similarly, an optimistic and a pessimistic prediction for completion cost of the project are calculated

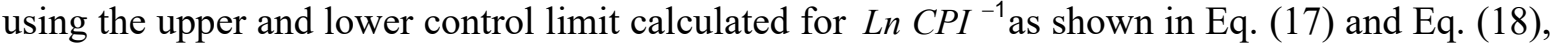
respectively:

$$
\begin{aligned}
& E A C(c)_{O}=A C+\frac{B A C-E V}{e^{U C L\left(C P I^{-1}\right)}} \\
& E A C(c)_{P}=A C+\frac{B A C-E V}{e^{L C L\left(C P I^{-1}\right)}}
\end{aligned}
$$

where, $E A C(c)_{O}$ and $E A C(c)_{P}$ represent the optimistic and a pessimistic prediction for completion cost of the project respectively.

\subsubsection{Selecting the best action plan}

Based on the control limits calculation discussed in subsection 3.2, the selected indicators are categorized into four zones named $A, B, C$, and $D$, as presented in Table 1. This table helps us for better classification for project status.

Table 1

Information of the case study at start point

\begin{tabular}{cc}
\hline Zone Name & Zone Range \\
\hline $\mathrm{A}$ & $(-\infty, L C L]$ \\
$\mathrm{B}$ & $(L C L, \mu]$ \\
$\mathrm{C}$ & $(\mu, U C L]$ \\
$\mathrm{D}$ & $(U C L,+\infty)$ \\
\hline
\end{tabular}

The status of any project can be classified into six states (Kerzner, 2015). Then, six states for project performance including "Perfect", "Good", "Normal", "Caution", "Bad" and "Critical" states are defined, as shown in Table 2:

Table 2

Model States definition based on selected indicators zones

\begin{tabular}{ccc}
\hline State & $\operatorname{Ln~CPI}^{-1}$ & $\operatorname{Ln} S P I(t)^{-1}$ \\
\hline Perfect & $A$ & $A$ \\
Good & $B$ & $A$ \\
Normal & $A$ & $B$ \\
Caution & $B$ & $B$ \\
& $C$ & $A$ \\
Bad & $A$ & $C$ \\
Critical & $C$ & $B$ \\
& $B$ & $C$ \\
\hline
\end{tabular}

Based on the defined states, the best action plan for each project phase is obtained using expert opinions.

\section{Implementing the proposed method on a case study}

In this section, the duration and cost forecasting methods introduced in a real project are implemented and the best action plan is selected. Hence, a case study is introduced, and after calculating the control limits for the indicators, duration and cost of projects are estimated. 


\subsection{Introducing a Case Study}

In this paper, the information from a database introduced by Batselier and Vanhoucke (2015) is chosen as a case study. This database is available in (OR-AS, 2019). The selected project is about the construction of a residential building in the Netherland. The summary of the approved project information is shown in Table 3:

Table 3

Information about the case study at baseline

\begin{tabular}{cc}
\hline Planned Start & $30-04-2004$ \\
Planned Finish & $11-11-2005$ \\
Duration & 562 Days \\
Total Budget & $1236603 \$$ \\
\hline
\end{tabular}

\subsection{Calculating Control Limits}

To calculating control limits, current project information is needed. Project progress information at the end of the third month is depicted in Table 4:

\section{Table 4}

Information about the case study after four months

\begin{tabular}{cc}
\hline Date of Registry & $30-07-2004$ \\
Elapsed Time & 150 Days \\
Actual Cost & $350791 \$$ \\
Planned Value & $645300 \$$ \\
Earned Value & $398415 \$$ \\
Earned Schedule & 112.43 Days \\
\hline
\end{tabular}

Based on the above information, the indices $S P I(t)$ and $C P I$ are calculated as in Eq. (19) and Eq. (20):

$$
\begin{aligned}
& S P I(t)=\frac{E S}{A T}=\frac{112.43}{150}=0.75 \\
& C P I=\frac{E V}{A C}=\frac{398415}{350791}=1.14
\end{aligned}
$$

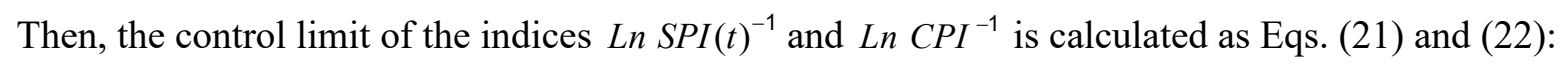

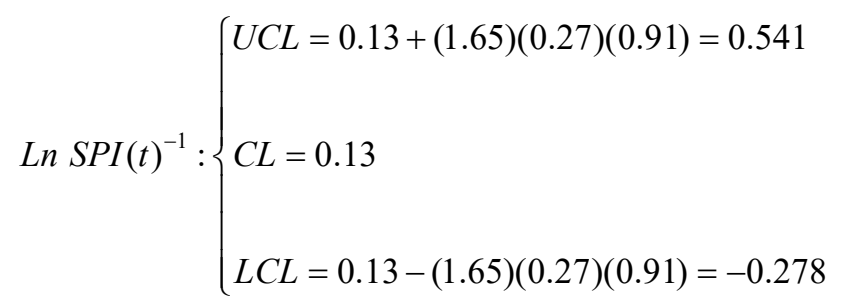

$$
\begin{aligned}
& \operatorname{Ln} C P I^{-1}:\left\{\begin{array}{l}
U C L=0.086+(1.65)(0.21)(0.86)=0.384 \\
C L=0.086 \\
L C L=0.086-(1.65)(0.21)(0.86)=-0.212
\end{array}\right.
\end{aligned}
$$

\subsection{Predicting the duration and cost at completion of the project}

After calculating the control limits of the mentioned indices, the duration and cost of completion of the project are predicted. 


\subsubsection{Duration Prediction}

The optimistic and pessimistic prediction of project completion duration is calculated as shown in Eq. (23) and Eq. (24):

$$
\begin{aligned}
& E A C(t)_{O}=A T+\frac{P D-E S}{e^{U C L\left(L n S P I(t)^{-1}\right)}}=150+\frac{562-112.43}{1.721} \simeq 412 \\
& E A C(t)_{P}=A T+\frac{P D-E S}{e^{L C L\left(\operatorname{LnSPI}(t)^{-1}\right)}}=150+\frac{562-112.43}{0.757} \simeq 744
\end{aligned}
$$

Thus, the estimated interval for the project time in days is obtained as shown in Eq. (25):

$$
E A C(t) \in[412,744]
$$

\subsubsection{Cost Prediction}

Similarly, the optimistic and pessimistic predictions of project completion cost can be obtained as shown in Eq. (26) and Eq. (27):

$$
\begin{aligned}
& E A C(c)_{O}=A C+\frac{B A C-E V}{e^{U C L\left(C P I^{-1}\right)}}=350791+\frac{1236603-398415}{1.468} \simeq 921764 \\
& E A C(c)_{P}=A C+\frac{B A C-E V}{e^{L C L\left(C P I^{-1}\right)}}=350791+\frac{1236603-398415}{0.809} \simeq 1386870
\end{aligned}
$$

Using the above results, we calculate the prediction interval of the project cost in the cost unit as shown in Eq. (28):

$$
E A C(c) \in[921764,1386870]
$$

\subsection{Analyzing Results}

To predict the project's duration and cost, optimistic and pessimistic predictions were calculated. The initial predictions for duration and cost of the project shown in Table 1 are within the prediction interval, which confirms the validity of the proposed method. Besides, a large percentage of the prediction interval for the project cost is less than the budget of the project at the project baseline. In other words, the centerline of the estimated cost of the project is less than the total budget of the project, which indicates the project is in good condition in terms of cost. Moreover, a large proportion of the predicted interval for duration is greater than the actual completion duration. It indicates that the project is likely to take longer than the projected duration.

\subsection{Selecting the Best Action Plan}

The information from a particular time track of the current phase of the project is obtained to select the best action plan. Hence, the information of the project after 180 days from project commencement are shown in Table 5:

\section{Table 5}

Information about the case study after four months

\begin{tabular}{cc}
\hline Date of Registry & $30-8-2004$ \\
Elapsed Time & 180 Days \\
Actual Cost & $704650 \$$ \\
Planned Value & $694700 \$$ \\
Earned Value & $630100 \$$ \\
Earned Schedule & 162.4 Days \\
\hline
\end{tabular}


Then, by calculating the $\operatorname{Ln} S P I(t)^{-1}$ and $L n C P I^{-1}$, and comprising the value of these indicators with the control limits calculated in subsection 4.2 , the current state of the project is determined. So, the current state of the project is "Normal". To obtain accurate information about selecting the best action plan considering the current states of the project from multiple perspectives, 24 experts from project management were interviewed. Hence, the best action in each state are gathered from experts, as shown in Table 6:

\section{Table 6}

The best action plan of the case study

\begin{tabular}{cc}
\hline State & The Best Action Plan \\
\hline Perfect & Positive Risk Exploitation \\
Good & Risk Acceptance \\
Normal & Risk Transference \\
Caution & Risk Mitigation \\
Bad & Risk Avoidance \\
Critical & Project redefinition \\
\hline
\end{tabular}

\section{Conclusion}

One of the most critical issues in projects is the calculation of the project performance. Several studies regarding project duration and cost predictions are made. A vast amount of mentioned studies proposed models to predict the future of the project. In all of the proposed models in the literature, the phase of the project is not considered, and they use a static approach to predict the final state of the project. Whereas there are many risks in projects and the nature of projects is unrepeatable. Besides, these models cannot provide any method to select the best action plan considering the current state of the project. Although the application of statistical methods in project management is not new, it is novel for simultaneous project duration and cost prediction and the best action plan selection. In this paper, a method for prediction of duration and cost of completion of the project is developed. This model provides an interval prediction of the future status of the project using the earned value management method. Moreover, this model can provide the best action plan based on the current state of the project dynamically. Also earned value management method is used as one of the most popular ways to measure project performance and project duration and cost prediction. There are three main advantages of the proposed method in the present paper. First, since control charts for the appropriate indicators are used in the proposed method, the accuracy of this model in predicting the duration and cost of the project is increased. Second, the possibility of selecting the best action plan to control and improve project performance is provided in this model. Third, this method is used in each phase separately, which leads to an increase in the accuracy of the model. Although, one of the main limitations of this research is that, since the best action plan is obtained using expert judgments, the sensitivity analysis on the result is impossible. Future research can overcome this limitation using a mathematical model to integrate forecasting the final state of the project and selecting the best action plan.

\section{References}

Baqerin, M. H., Shafahi, Y., \& Kashani, H. (2016). Application of Weibull analysis to evaluate and forecast schedule performance in repetitive projects. Journal of Construction Engineering and Management, 142(2), 04015058.

Batselier, J., \& Vanhoucke, M. (2015). Evaluation of deterministic state-of-the-art forecasting approaches for project duration based on earned value management. International Journal of Project Management, 33(7), 1588-1596.

Batselier, J., \& Vanhoucke, M. (2017). Improving project forecast accuracy by integrating earned value management with exponential smoothing and reference class forecasting. International Journal of Project Management, 35(1), 28-43.

Chen, H. L., Chen, W. T., \& Lin, Y. L. (2016). Earned value project management: Improving the predictive power of planned value. International Journal of Project Management, 34(1), 22-29. 
Colin, J., \& Vanhoucke, M. (2016). Empirical perspective on activity durations for project-management simulation studies. Journal of Construction Engineering and Management, 142(1), 04015047.

Fleming, Q. W., \& Koppelman, J. M. (2016, December). Earned value project management. Project Management Institute.

Ghorbani, R., Ghousi, R., \& Makui, A. (2019). Location of compressed natural gas stations using multi-objective flow refueling location model in the two-way highways: A case study in Iran. Journal of Industrial and Systems Engineering, 12(2), 95-112.

Guide, P. M. B. O. K. (2017). A guide to the project management body of knowledge. Sixth Edit. Project Management Institute, Inc.

Hunter, H., Fitzgerald, R., \& Barlow, D. (2014). Improved cost monitoring and control through the Earned Value Management System. Acta Astronautica, 93, 497-500.

Kerzner, H. (2015). Project management 2.0: leveraging tools, distributed collaboration, and metrics for project success. John Wiley \& Sons.

Khamooshi, H., \& Golafshani, H. (2014). EDM: Earned Duration Management, a new approach to schedule performance management and measurement. International Journal of Project Management, 32(6), 1019-1041.

Liu, S. S., \& Lin, Y. C. (2008). Project performance evaluation based on statistical process control techniques. Journal of Construction Engineering and Management, 134(10), 813-819.

Lipke, W. (2002). A study of the normality of earned value management indicators. The Measurable News, 4(1), 6.

Lipke, W. (2003). Schedule is different The Measurable News. College of Performance Management of the Project Management Institute.

Lipke, W., Zwikael, O., Henderson, K., \& Anbari, F. (2009). Prediction of project outcome: The application of statistical methods to earned value management and earned schedule performance indexes. International Journal of Project Management, 27(4), 400-407.

Martens, A., \& Vanhoucke, M. (2018). An empirical validation of the performance of project control tolerance limits. Automation in Construction, 89, 71-85.

Mortaji, S. T. H., Noorossana, R., \& Bagherpour, M. (2015). Project completion time and cost prediction using change point analysis. Journal of Management in Engineering, 31(5), 04014086.

OR-AS. (2019, November 13). Retrieved from Online consultation of the real-life project database Website: Web site: http://www.projectmanagement.ugent.be/research/data/realdata

Valle, J. A., \& Soares, C. A. P. (2006). The use of earned value analysis (EVA) in the cost management of construction projects. In Proc., Project Management Institute Global Congress, Newtown Square, PA (pp. 1-11).

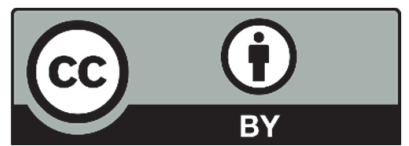

(C) 2020 by the authors; licensee Growing Science, Canada. This is an open access article distributed under the terms and conditions of the Creative Commons Attribution (CC-BY) license (http://creativecommons.org/licenses/by/4.0/). 